This item was submitted to Loughborough's Research Repository by the author.

Items in Figshare are protected by copyright, with all rights reserved, unless otherwise indicated.

\title{
Design for sustainable behaviour: a case study of using human-power as an everyday energy source
}

\section{PLEASE CITE THE PUBLISHED VERSION}

http://dx.doi.org/10.1504/JDR.2016.10000589

\section{PUBLISHER}

(C) Inderscience

\section{VERSION}

AM (Accepted Manuscript)

\section{PUBLISHER STATEMENT}

This work is made available according to the conditions of the Creative Commons Attribution-NonCommercialNoDerivatives 4.0 International (CC BY-NC-ND 4.0) licence. Full details of this licence are available at: https://creativecommons.org/licenses/by-nc-nd/4.0/

\section{LICENCE}

CC BY-NC-ND 4.0

\section{REPOSITORY RECORD}

Shin, Hyunjae Daniel, and Tracy Bhamra. 2019. "Design for Sustainable Behaviour: A Case Study of Using Human-power as an Everyday Energy Source". figshare. https://hdl.handle.net/2134/22201. 


\title{
Design for sustainable behaviour: a case study of using human-power as an everyday energy source.
}

\author{
Hyunjae Daniel Shin* \\ School of Architecture Design and Built Environment \\ Department of Product Design \\ Nottingham Trent University \\ Burton Street, NG1 4BU, Nottingham, UK \\ Email: daniel.shin@ntu.ac.uk \\ *Corresponding author \\ Tracy Bhamra \\ Loughborough Design School, \\ Loughborough University, \\ Leicestershire, LE11 3TU, UK \\ Email: t.bhamra@lboro.ac.uk
}

\begin{abstract}
There is an increased focus on research identifying design strategies to influence user behaviour towards more sustainable action, known as Design for Sustainable Behaviour (DfSB). Recent literature in this field has introduced a number of design processes, and developed a model that emerged through consensus. However, not enough case studies are accompanied by those proposed strategies; therefore it is difficult to evaluate their effectiveness. This paper presents findings from a case study of inducing a sustainable behaviour - using human-power to drive an everyday Energy using Products (EuP). It presents the result of applying the strategy to an artefact and evaluation was carried through conducting a product-in-use study. The analysis provide an explanation of how each of the participants cope with the use of new artefact and account for different types of motivations that have affected on their behaviour determinants.
\end{abstract}

Keywords: design for sustainable behaviour, feedback, human-powered products, energy consumption

Reference to this paper should be made as follows: H. D. Shin and T. Bhamra. (xxxx) 'Design for sustainable behaviour: a case study of using human-power as an everyday energy source’, J. Design Research, Vol. X. No. Y, pp. 000-000.

Biographical notes: Hyunjae Daniel Shin is a Senior Lecturer in Product Design at Nottingham Trent University. His $\mathrm{PhD}$ explored the role of design for inducing sustainable behaviour of using humanpowered products. His research interest focus on the use of design-led interventions to promote sustainable behaviour within domestic environment; investigating the benefits of human-power products for improving health and well-being. His future research will focus on the role of design and measures of internalising sustainable behaviour.

Professor Tracy Bhamra is Professor of Sustainable Design and Pro Vice-Chancellor (Enterprise) at Loughborough University. She has a BSc and MSc in Manufacturing Systems Engineering and completed a PhD in Design for Disassembly and Recycling at Manchester Metropolitan University in 1995. In 2003 she established the Sustainable Design Research Group at Loughborough University that undertakes world-leading research in areas such as Design for Sustainable Behaviour, Methods and Tools for Sustainable Design, Sustainable Product Service System Design and Sustainable Design Education. Tracy is a Fellow of the Institution of Engineering \& Technology (FIET), the Design Research Society (DRS) 


\section{Introduction}

Today, energy consumption has become the norm of accomplishing everyday tasks through use of a range of electrical products; however, energy itself is invisible during use. Despite dramatic issues of resource depletion, these electronic era that we live in has aggravated overconsumption in the electrical (consumer electronics) energy sector (Owen, 2012). Creating energy-efficient technologies is the first necessary and important step towards sustainable energy consumption and to prevent such a crisis; however, it is only a partial solution.

Many authors (e.g. Owen, 2012; Palmer et al., 2012) emphasise the notion that perhaps future approaches should also take account of an understanding of why and how people consume energy. Whilst future industries will inevitably focus on the development of energy efficient technologies and its integration into everyday products, a new approach may achieve stronger effects, where behavioural change can also have an impact (Lilley, 2007). The question of how to make people more conscious and aware of their energy consumption is perhaps now more relevant than it has ever been, making energy visible and even tangible.

While early eco-design research in the energy sector focused on increased energy efficiency, in recent years a 'design for sustainable behaviour' (DfSB) has received growing interest (Boks, 2012; Lilley, 2009; Lockton et al., 2008; Selvefors et al., 2011). It aims to reduce behaviour related environmental impacts through the (re)design of products or services using techniques from social psychology, persuasive technology, or interaction design, shifting user behaviour towards more sustainable action. In this paper, a case study is presented of inducing sustainable behaviour - using human-power to drive an everyday Energy using Products (EuP). It presents the key elements for inducing a new behaviour and a design strategy to put these actions into a routine. The paper presents the result of applying the strategy to an artefact and the evaluation carried out through conducting a product-in-use study. The study should be seen as an empirical investigation and its results contribute to advancing the knowledge of Design for Sustainable Behaviour.

\section{Design for Sustainable Behaviour}

It is widely accepted that the use-phase of the electrical product's life cycle is the most significant in the context of energy consumption, and mostly, this is determined by user 
behaviours (Lilley, 2007; Lockton et al., 2008; Tang and Bhamra, 2008; Wever et al., 2008). Therefore, design strategies for bringing a behavioural change have emerged and spurred by increased focus of research on the environmental consequences of behaviour.

\subsection{Strategies for DfSB (Design for Sustainable Behaviour)}

One of the early principles used in 'design for sustainable behaviour' (DfSB) is the 'script' approach mainly introduced by Jelsma and Knot (2002, p. 120), and described it as 'a product layout guiding the behaviours of the user, in a more or less forceful way'. The approach enables users to perform certain behaviours through scripted design of value, incentive and rules that are embedded in between the service and product. However, the 'script' can also constrain certain behaviours through design characteristics such as shape, mechanism, and signals. Norman (1999) describes this condition as affordances and constraints; appearance of the device providing clues to operate. For preventing certain actions, Norman introduced 'forcing function' where one condition must be complied with, without consciously processing information relevant to that action, before a function is enabled, e.g. an interlocking seatbelt ${ }^{1}$.

Along with growing interest for DfSB a number of different design strategies have emerged (Lilley, 2009; Selvefors et al., 2014; Wever et al., 2008; Zachrisson and Boks, 2012). While many frameworks have a different emphasis and some disparate interpretations, Figure 1 shows the summary of approaches using an axis of 'power in decision making' which was developed by Lilley and Wilson (2013). Although orientation of these strategies differ to each other, their spectrums analogous with Norman's view of 'affordances' and ‘constraints'. As an axis shows, the delegation of control on making the behavioural change decision lies either with user or product or in between. On the left where the user is in control, examples introduced by scholars have characteristics of strategy that inform the consequences of changed behaviour. Often, information is given through a system of feedback where decisionmaking is enabled by learning and knowing the forthcoming consequences and therefore stimulates to change. On the right of axis are strategies that have characteristics of either: preventing unsustainable behaviours by coercion (through design), or making them sustainable, or inducing sustainable consequence through a collateral system (e.g. integrated

\footnotetext{
${ }^{1}$ Interlock seatbelt system doesn’t allow engine to start until driver passenger fastened their seatbelt.
} 
toilet and $\operatorname{sink}^{2}$ ). In the middle, there is varying degree of delegation of control which is similar to a 'script' approach.

Beyond the strategies shown, recent literature in this field has introduced a number of different design processes, and developed a model that emerged through consensus (Bhamra et al., 2011; Selvefors et al., 2011; Tang and Bhamra, 2012); developing tools for designers and practitioners (Zachrisson and Boks, 2014); building evaluation methods (Wilson et al., 2013); and also an ethical assessment tool (Lilley and Wilson, 2013). Whilst there is some commonality in the model, the lack of case studies at present makes the evaluation of identified design process difficult. A set of empirical and conclusive results are crucial to evaluate the effectiveness for each and as yet not enough case studies are accompanied by the proposed strategies. With understanding of its importance, it was noted that practical considerations and limitations of these DfSB stratagems need to be further discussed through longitudinal studies (Wilson et al., 2015).

Looking from an ethical perspective, concerns exist with types of intervention using strategies such as force, stealth, or automation. As Brey (2006) argued, people’s autonomy may be threatened when their essential everyday actions are 'trained' by these types of behaviour steering technologies. To some extent, these technologies instead make goals and plans on behalf of users, whereby humans are no longer autonomous decision-makers. However, depending on the urgency of the problem, these strategies can overturn the notion where preventing unsustainable behaviour, especially by stealth (Lilley et al., 2005), can be most effective in increasing the impacts without risking user acceptance (Jackson, 2005; Rodriguez and Boks, 2005). Therefore, it is the designer's discretion to select the strategy based upon situations; but on the other hand, it is important to account and fully integrate the inherent ethical consideration within the DfSB process (Lilley and Wilson, 2013).

\subsection{Design for sustainable energy consumption}

The energy use turns out to be a 'low interest' interaction due to its cost not significantly affecting the overall household budget, as yet, although they regard electricity (energy) as a necessity (Fischer, 2008). Therefore, research on making energy more visible has received increasing attention over the last years (Darby, 2006). Devices such as 'Smart Meters', also

\footnotetext{
${ }^{2}$ Water used for hand washing in the sink flows into the cistern to ultimately flush the toilet, therefore saves water.
} 
called In-Home Displays (IHD) by Strengers (2011), ‘eco-feedback’ is a typical interactive feedback system that visualise the energy use. These type of feedback systems play significant roles in raising energy awareness and achieving reduced energy consumption of the order of $10 \%$ (Darby, 2001, 2006), and increase the reduction of demand at peak times (Carroll et al., 2014).

Eco-feedback systems, in theory, may be recognised as an applicable method for increasing the awareness of one's behaviour; however, it may only appeal to those who are environmentally motivated, and conservation benefits may reduce over a period of time (Hargreaves et al., 2013). Thus, it was suggested for such systems to design with high accessibility rather than merely increasing the frequency and transparency of feedback (Kobus et al., 2015). Therefore, disciplines such as HCI and interaction design seem to have promising opportunities, especially for designers, as to increase the effectiveness of feedback systems; being more interactive and frequently communicating compared to conventional methods (e.g. paper-based). Recently, empirical evidence is being reported through studies that investigate the effectiveness of; alternative forms of eco-feedback such as ambient feedback display (e.g. Broms et al., 2010; Kim et al., 2010); frequency of information displayed (Fitzpatrick and Smith, 2009; Hargreaves, 2010); and using online eco-feedback systems (Selvefors et al., 2013).

A good example that can be categorised within the middle axis of DfSB strategy (See Figure 1), and in relation with energy consumption is a 'Flower Lamp' (Figure 2) developed by Backlund et al. (2007). The concept explored the design as a tool to encourage energy reduction in the home. It is a feedback display system that tracks the energy consumption, but not as in a display unit that shows quantifiable units. If the household has a decrease in electricity use over the course of weeks and months, the lamp rewards the user by slowly opening up to represent a 'blooming' flower. If, on the other hand, energy use is increased, the lamp closes back to its original shape. This example reflects a design intervention that is designed to show the consequences of user's own energy consumption through a system of feedback. It uses 'reward' and 'penalty' techniques to steer new behavior towards lowering energy consumption. Although the form of consequential information is given in a 'long-term frequency' (weeks or months), it encourages users to have control over their consumption and achieve 'sustainable energy consumption' at a macro level. Instead of using the display to show tangible incentives like cost, the role of design focused on providing psychological 
factors of 'aesthetically rewarding' symbolic flower to influence and change the energy consumption pattern; and vice versa it can also work as stimulus of 'penalty' when the lamp closes. However, the technique used in this intervention only provides psychological factors and does not limit or engage users’ behaviour into a forced functionality (Wever et al., 2008). The design element in this type of intervention delegates a free space for the inclusion of user's autonomous interaction and increase the relation between product and user that is created through spontaneous occurrences.

\subsection{Maintaining the behaviour}

Shifting consumption patterns depends on the thorough understanding of not only what motivates users, but also on how behavioural change gets formulated; and how it can be influenced through applied interventions (Jackson, 2005). It has been argued that one-sided emphasis of an intention, attitude or individual motives are only effective in the short-term; and that the most important aspect in behavioural change is the process of re-routinising the de-routinised behaviours (Spaargaren, 1997). De Young (1993) argues that real challenges in changing behaviour should focus on maintaining the stability of changed behaviour, and at the same time, minimising or eliminating the need for repeated intervention. In addition, the effectiveness of interventions depend upon the process of changing existing habits, initiating new behaviour, and the maintenance of that behaviour (Steg and Vlek, 2009; Verplanken and Wood, 2006). Thus, interventions that merely stimulate extrinsic motivations may fail as they become obsolete, so does desired behaviour.

Similar to Jelsma and Knot (2002) argument of 'in a more or less forceful way', Wever et al. (2008) argue that behaviours can be either induced or forced. Nonetheless, most of intelligent products (e.g. integrated toilet and sink) may not seem to have the process of 'deroutinisation' since its scripted design, rather 'unscripted' or by 'stealth' as described by (Lilley et al., 2005), exists at current behaviour instead of requiring a new behaviour. For designers applying DfSB, it is important to consider the particular processes that influence the behavioural change at different stages. Early stages may be more relevant for increasing the awareness but the latter should be considered for reinforcing the choices and to maintain the intended behaviour. 


\section{Using human-power as sustainable behaviour}

Humans began to gradually less use their own muscle power since the invention of powerful motors and electricity became more common in use (Dean, 2008). As recently as 150 years ago, human-powered products (HPP) were the norm in every nation, e.g. hand crank grinder, bicycle, pedal powered lathe and sewing machine. However, as the electro-mechanical motors developed and became more widespread, everyday 'products' have evolved significantly. Simultaneously, using human-power for powering such products has also gradually diminished (Dean, 2008). Human-powered products (HPP), as perceived in recent research literature as alternative power source for battery running electronic products (Jansen, 2011; Jansen and Stevels, 2006; Jia and Liu, 2009), is considered as one solution to reduce the environmental impact of products, including problems such as the over-consumption of energy (electricity) caused by increase of EuP. In other words, users of HPP no longer rely solely on the use of electricity from the grid to drive the EuP in use.

The study on HPP mainly focussed on identifying the barriers and suggestions in the engineering design of human-powered energy systems, life-cycle of HPP and broadening the knowledge required during the design process; and they were based upon a scientific approach (Jansen, 2011). However, no such theoretical framework was identified in relation to how people use HPP in their daily practice, more pertinently, how people acquire and organise a new behaviour of using human-power as an alternative source for powering EuP.

\subsection{Does human-power save energy?}

The cost factor may be a real influencer when using HPP over using the grid power such as amount of potential saving and its unit of cost. The benefits, although it can be subjective, may contrast to what actual consumers expect from using the HPP. For example, running a 100 watt TV for an hour will cost about average of $£ 0.0145^{3}$ in the UK. Eventually, this figure would also be the cost saved when energy was powered by human-power system. Moreover, it could be seen more sceptically when considering the cost and overall environmental impact value of generating human-power source - the calories consumed through food. From life-cycle perspective, the true benefit could only be realised by calculating the break-even point, e.g. the time required for generating the incentive that is larger than the cost invested. However, similar to the cost involved in food consumption, low

\footnotetext{
${ }^{3}$ Average electricity cost in the UK is $£ 0.145$ per kWh. $(100 \mathrm{~W} / 1000) \times 1$ Hour $=110$ Watt.
} 
prices of fossil fuels are masked expenses beyond what it costs at production. These expenses may encompass human-health problems caused by air pollution from burning coal, global warming and so on (Armaroli and Balzani, 2007).

Meanwhile, academics in this field have emphasised the intangible and long-term based advantages of HPP such as long shelf life (no battery replacement), available on demand, and feeling environmentally pro-active (Jansen, 2011; Jansen and Stevels, 2006). But most of all, using human-power can emanate from intentions and motives of practicing alternative way of using energy which has been done passively to date. To add another dimension, the size of cost saving may not be a significant motivator to maintain the use of HPP; but on the other hand, the value may appear much greater when the number of HPP increases and more people begin to use HPP. For example in the UK, approximately 32\% of adults spend 6 hours of sedentary time on weekdays (Townsend et al., 2012). If these individuals spend half of their sedentary time generating power to run a TV using a pedal-powered bike approximately $£ 49$ million $^{4}$ worth of electricity could be generated per year.

However, the enthusiasm of human-power inventors and its users emphasise the notions of 'empowerment' which gives control over energy use - generating the power in need whenever without relying on the power from the grid. In the context of the energy sector, increasing the energy efficiency of electronic devices already brings a reduction in a longterm energy demand. For example, as a result of the EICTA ${ }^{5}$ unilateral voluntary agreement introduced in 1997, new TVs use significantly lower standby power than older models. In a similar context, it is anticipated that benefit of HPP will soon be realised more widely due to the increase in energy efficiency of electronic devices, meaning that electronics will shift towards ever-decreasing wattage requirements. This shift makes the use of human-power more feasible as an alternative energy source and it will provide more opportunities in much broader ranges of electronic devices.

In spite of the small cost savings, it is not yet known how actual users of HPP would value these incentives. Therefore, this notion also builds on to the necessity of conducting an empirical study that aims to understand how the actual consequences of using existing HPP

\footnotetext{
${ }^{4} 20$ million (32\% of UK population) x $0.11 \mathrm{kWh}$ (average TV consumption) x 3 hours (half of 6 sedentary hours) x 52 weeks x $£ 0.145$ (Price per $\mathrm{kWh})=£ 49$ million.

${ }^{5}$ European Industry Association for Information Systems, Communication Technologies and Consumer Electronics
} 
are influencing consumer decisions, and their determinants. Not all users will purchase such HPP for the purpose of reducing electricity consumption nor for the cost benefit; it is also argued that not all cyclists are doing so to reduce fuel consumption for transportation. Rather, application of certain aspects like communication, feedback, or other types of moral empathy between the product and user is perhaps a more relevant issue for users of this type.

\section{Methodology}

The results of research work discussed in this paper were obtained through the use of an artefact in the form of a prototype, with the user scenario of using human-power as alternative to non-renewable energy source; and by means of practicing a new sustainable behaviour. In order to understand the current perception of HPP among the public, the study focused on how people comprehend the use of human-power within its real-life context and their accepted value. It focused on understanding the 'product experience', more precisely, all possible affective experiences involved in the interaction of using HPP as an everyday energy source to power EuP.

\subsection{HUS}

Using a 'product' to capture or understand the in-context behaviour is called 'Product-in-use' (Evans et al., 2002) which often uses a video equipment to recognise the problems in real life setting. Similar to the 'Product-in-use' approach, the term IHUT (In Home User Test) is also widely being used in different professions as one technique from marketing research. It is a cost effective way to test commercial driven products with real consumers before commencing to actual market launch. Its approach asks consumers to use the product at home in their own environment rather in a closed room such as focus group. The term HUS (Home User Study) was chosen to name this HPP study which reflects the investigation of behaviour involved in the use of HPP by real-life practitioners. The intention of HUS was not to evaluate and assess the HPP per se, but to gain a deeper insight into what it means to use human-power as alternative source of everyday energy; and moreover, how the design of new HPP (prototype) helped to put this behaviour into a routine practice. In order to construct the meaning of behaviour involve in the use of HPP, it was recognised that a prolonged investigation period of 'actual use' was vital. 
In order to investigate the meaning of HPP use and its consequence, total of three replicative case studies were conducted. The results of first two case studies generated great insight into the actual use of existing HPP and revealed the behavioural problems that helped in iterating and enhancing the design of the prototype used in the present study. As the final study dealt with understanding the use of new HPP, an appropriate sampling process was required to obtain a suitable group size. These potential users required the intention and willingness to experience such product-led intervention to drive everyday EuP. These individuals were recruited through online survey filtering. The purpose of the survey was to understand their level of previous experience with HPP as well as their demographic information to conduct the HUS; and topics related to energy usage. A total of 29 questions were designed to obtain data from 143 respondents with a complete response rate of 92\%. Final 14 individuals from 10 households were filtered based on household location, occupancy, and those who favoured the idea of using the human-power as everyday energy source.

\subsection{Research Artefact}

In making a new prototype that can conceptualise the behavioural change and induce a preferred state of HPP use, it emerged that human-powering a 'Television' was most suitable for HUS. TVs are one of the largest electricity consuming appliance in Information and Communications Technology sector. Manufacturers have been introducing low energy consuming TVs, but TV ownership has continued to rise, e.g. buying new and old TVs moved to a different room (Bertoldi and Atanasiu, 2007). More recently reports also confirm an increase in 'time spent watching TV' in UK. Ofcom (2013) reported that people aged 4+ spend average of 241 minutes of TV watching per day in 2012, which is increased by 23 minutes from year 2007.

In addition, Crosbie (2008) has identified that heavily energy intensive consumption behaviours are encouraged by the design, marketing of TV, and individualised electronic entertainment. Moreover, reconfigured homes and lifestyles are now changing to fit these new product/services and therefore it makes increasingly difficult for households to reduce their energy consumption. However, it is important to highlight that the focus of study is not realising the behaviour around TV usage, but selecting a common electronic product to elicit an understanding of human-power use. In order to generate an adequate amount of power to drive the TV, an electricity generating bike (E-Bike) was added to the prototype. This is due 
to the findings from initial two studies which revealed that the physical movement of 'pedalling' is seen as a skill derived from pre-established competence and has been prolonged. Therefore, it was decided that this method of power-generation would be suitable, avoiding any rejection arising from complex usability of new HPP prototype.

It was discussed that a co-existing benefit in the use of HPP and the size of the potential saving may not be a significant motivator in sustaining the use of HPP. Therefore, it was required to develop a prototype that can perhaps impact upon extrinsic motivation by increasing the power output. It was found that typical power output of pedal power generator produces in range of $100 \mathrm{Watt}$ and up to $300 \mathrm{Watt}$ maximum. This range of power output can potentially power flat/LCD/LED televisions, but the run-time varies depending on the screen size. An average TV consumption rate was obtained of 110 Watt from examining 405 TV brand listings. With varying ranges of wattage output, the new HPP prototype's performance was set to match a condition where 30 minutes of pedalling gives enough power output for one hour of TV (110 Watt) watching.

Another major enhancement in making the new prototype was embedding a feedback system. Figure 3 illustrates how the new HPP system operates. In order to watch 1 hour of a 110 Watt $\mathrm{TV}$, the user is required to exert approximately 30 minutes of pedalling on the E-Bike to reach 360 units of battery capacity ${ }^{6}$. The present study also attempted to challenge the existing DfSB methods by designing a HPP that can be in a state of flux within the spectrum. Instead of choosing a strategy, it attempted to design an artefact that can respond to user with different strategies, particularly using the three strategy outlined by (Wever et al., 2008). As the user exerts human muscular energy by pedalling on the E-Bike, the corresponding amount of charged energy is shown through a display in an incremental unit (counts up). However, as the user plugs a TV adapter into the power inlet and as the power current flows, the unit display shows the corresponding power loss (counts down). By providing the consequential feedback of power allowance, it uses the 'eco-feedback' strategy. However, it also uses the 'script' approach, as it draw users 'in a more or less forceful way', to coercively motivate them to exert human-power in order to watch the TV on demand. The bottom image of

\footnotetext{
${ }^{6}$ Measured average pedalling with students, it was configured that the range between 360 to 400 units (30 minutes of pedalling) was appropriate level which is equivalent to 1 hour worth of unit from watching 110 Watt Television.
} 
Figure 3 shows how the TV switches off when the unit of battery reaches zero; in this case, it is using the strategy of 'forced functionality'.

\subsection{The Approach}

The HUS was scheduled for three visits at an interval of one week. On the first visit, a smart meter was placed to measure the household TV consumption and hours of watching. These measurements were compared with usage during the HUS (using new HPP system) and shown to participants during the interview. The purpose was to discuss the notion of 'saving electricity' and how these external benefits influence their motivation for further use. The second visit took place a week after the first visit, deploying the new HPP system in their home.

An in-depth interview was the foundation of final visit. The very essence of this interview analysis focused on understanding the meaning of particular phenomenon to the participants, where explanatory work was required to understand different types of motivations. Therefore, a qualitative interview was used to collect a substantial amount of data that is derived from the direct users of the new HPP. As these interview were semi-structured, the interview guide was applied flexibly under the topic of 'energy saving behaviour' and the effectiveness of new HPP-use was central to the development of the interview guide. The interview lasted no more than an hour, minimum of 30 minutes. All interviews were both video and audio recorded for later use, and transcribed into coding software (Nvivo).

\subsection{Analysis Methods}

Ryan and Deci (2000) argue that people may show a lack of desire in changing their behaviour, but it can be controlled by different types of external motivations. These motivations will vary depending on the extent to which they are controlled, sometimes punished or become autonomous through their feeling. The end goal of any behavioural change technique would be to elicit a condition whereby people become self-determined as they enact the regulations and find the related behaviour as important. Ryan and Deci (2000) calls this process as 'Internalisation' where people begin to 'take in' a value of regulation. Whilst the participants showed initial motivations of having an intention of changing behaviour, it was important to understand how they perceive the different motivational factors to predict the internalisation of new HPP use. 
Therefore, the focus of the analysis was to provide an in-depth explanation of how each of the participants coped with the use of human-power to watch their TV. In doing so, it followed a deductive approach by using a priori template of codes outlined by Crabtree and Miller (1992). Regulatory styles presented by Ryan and Deci (2000) was used as basis to categorise the codes describing different form of motivations, and explanations on how they may affect participant behaviour change (See Figure 5). These explanations connect to themes that account for whether they have reached an internalisation of the new HPP use and an understanding of the effectiveness of the implemented design strategy; or alternatively, barriers in regulating their intended behaviour.

\section{Findings}

\subsection{Initial Motivations}

In accounting for different phases of the internalisation process, it was very important to identify their initial motivations for participating in the HUS. The majority of participants had an interest in reducing the energy consumption. These self-interests were also related to the notion of "alternatives efforts of powering home" (P-04) that are derived from the "idea of the sustainability and generating some of your own electricity instead of depending” (P-07). The idea of being 'off the grid' also derived from their motivations towards practicing alternative way of consuming energy which has been done passively to date. In addition to above the mentioned initial motivations, many described their motivation in relation to obesity concern and issue of suffering from physical inactivity.

\subsection{Extrinsic Motivations}

Although many HPP users accepted its use from 'interest' (intrinsic motivation), it was evident that the size of the incentives (external motivation) were less of a significant motivator for further use. The majority of participants have commented that their expectations on saving were much higher. However, it was noted that extrinsic motivations can be controlled invariably and become 'internalised'. The following sections present different types of motivation shared by participants which were grouped into themes of regulatory styles. 


\subsubsection{External Regulation}

Externally regulated behaviours are described as extrinsically motivated behaviours that are least autonomous (Ryan and Deci, 2000). These behaviours are performed to satisfy an external demand (by others), controlled or alienated, or reward contingency. In identifying the codes within this theme, a number of comments were related to how a household used the new system of HPP as tool to regulate their children's TV usage. Participants such as P-05 and P-12 who both have children used the study as an opportunity to control the children's excessive use of ICT related products. For example, P-12 described how this HUS became a compromise through making her child give some effort in order to earn the reward of watching TV: "I think it is particularly good for the kids. Because we are always trying... let's not watch too much TV, and it makes exercise more and it feels like it compromised that you can watch TV too". An intriguing comment was received from P-05 that emphasises this particular phase of the internalisation process, that is people realising that the external rewards are contingent upon their effort. In other words, the HUS made people view energy use as 'take it from earned' instead of 'take it for granted'. P-07 described this concept as “ $I$ like the idea of 'put something in' to 'get something out'”. It can be seen that the external regulations identified in this phase enables a critical reflection of energy consumption and the new practice that emerges and moves energy use from an 'inconspicuous' state to ‘conspicuous' routine.

\subsubsection{Introjected Regulation}

While external regulation refers to a phase when users begin to realise a potential or possible increase in external benefit, the introjected regulation is a second type of extrinsic motivation in which behaviours are performed to avoid guilt or anxiety (Ryan and Deci, 2000). These type of behaviours involve users taking in a regulation but not fully accepting it as their own. Often, these behaviours are performed to attain ego enhancements or represents regulations gained through self-esteem in which people are motivated to avoid failure. Similar phenomenon was observed through participants' interview. P-13 described himself as a competitive person who tries to avoid being worried about things, e.g. "see my psychology wouldn't let me go to zero (the unit on new HPP)", "I would rather put in hard hours at start and never worry about it”. Whereas P-09 commented about how her intention aimed to ensure the reward by making a conscious effort: "I would make a conscious effort to then get to a certain maybe like 300 (unit) or something before... I got enough time to watch. So think that was more driven by ensuring we had enough time rather than exercising...”. Again, it 
can be seen that these type of behaviours were only possible through interacting with the HPP system, particularly with the system of feedback.

Similar to the intention of P-13 where his behaviour was performed to avoid punishment, the most commonly mentioned word was the competition. The interaction not only provided an alternative way to watch TV, but the feedback display also helped people to induce a competition between household occupants. P-14 described how his children were competing with each other: "I think they were definitely noticing that it was going up ...They wanted to see who can put it up the most". This phenomenon of what might be described as 'attaining ego enhancement' were perceived as a 'game' to other participants. For example, P-02 explains how he viewed his behaviour as "I think immediately it turned into a game. Simple Game. If I pedal faster, then the numbers go up more quickly", and P-04 described it as "it is a big gaming thing sort of".

Above all, the most intriguing part of ego-involvement was derived from a notion that the majority of participants found HUS interesting due to the need of exercise and growing apprehension that people suffer from physical inactivity. It was noted that the average TV watching time in UK has increased to 4 hour per day (Ofcom, 2013). Moreover, concerns were raised over the fact that the third most popular activity carried out by people in Great Britain was watching TV/videos/DVDs or listening to music (Energy Saving Trust 2007). The behaviour around TV watching contributes to sedentary behaviour (Veerman et al., 2012), e.g. too much sitting, as distinct from too little exercise. Veerman et al. (2012) argue that TV viewing time may also be associated with a reduction of life expectancy that is comparable to other major chronic disease risk factors such as physical inactivity and obesity $^{7}$. However, this does not mean that they participated in the HUS purely for exercise reasons but rather they favoured the idea of it producing more than one benefit of "enhance my well-being, and there are benefits to planet as consequence” (P-03). While the external benefit such as 'cost saving' was not a significant motivator, but using human-power can offer additional benefit that is beyond off the grid power. Human-power enthusiasts suggest that HPP is a cost savings for society, as it offsets the health conditions caused by physical inactivity (Dean, 2008).

\footnotetext{
${ }^{7}$ Veerman et al. (2012) quantified the impact on life expectancy from TV viewing. The result shows that every single hour of TV viewed after the age of 25 reduces the viewer's life expectancy by 21.8 minutes.
} 


\subsubsection{Identified Regulation}

The behaviours discussed in the phase of identified regulation can be seen as more autonomous. Although behaviours are mostly motivated through extrinsic factors, it is done solely as a source of spontaneous enjoyment and satisfaction. The identification refers to a conscious valuing of a behavioural goal or regulation, therefore the user accepts the action as personally important (Ryan and Deci, 2000). The intention of these behaviours are endorsed by themselves, and expects to have a greater chance of being maintained and to be associated with higher level of commitment. During the course of HUS period many participants identified with the importance of either exercising regularly or accepting a regulatory behaviour to watch TV for their own right. Most of the participants recognised their behaviour as valuable, and voluntarily put those behaviours into a routine. Whether the behavioural goal was related to improving health or to increase their contribution to energy saving, participants began to consciously value their behavioural consequences. For example: "I know I'm saving little, but it will be like you are doing something beneficial for yourself as well as maybe saving little bit of money. But it will be more about... you would be doing something, you are powering something, and benefiting your own well-being at the sometime. So I think that would be more the motivator for me rather than the money saving" (P-16).

\subsubsection{Integrated Regulation}

The final phase of internalisation, the most autonomous form of extrinsic motivation is integrated regulation (Deci and Ryan, 2000). In this phase, the initially perceived external regulation assimilates into self-regulation and the result is self-determined extrinsic motivation. However, it is not argued that participants in HUS must progress through each regulatory phase. Rather, it was observed that new behavioural regulations can be developed at any given phase within the internalisation process.

Despite the low cost benefit, participants identified with the importance of behaviour which showed their motivation to continue to use human-power as an everyday energy source. This new behaviour and its internalised routine of use were formulated through; 'de-routinising' precedent patterns of energy consuming behaviour; and through 're-materialising' the inconspicuous energy consumption habits; and 're-routinising' that behaviour through an internalisation process. For example, the comments below illustrate how participants described this routinised behaviour: "Initially I just get one and just feel like 'oh I just do half 
an hour or so'. But then you get slightly addicted when you can see the box racking itself up" (P-09). The theme of 'Cycling as a habit' emerged within this category where some participants described how the use of the new HPP became a habit of:

"But I got into a habit of...thinking that I have to do sort of 10 15 minutes of bike when I get back from work... spend some time on the bike" (P-03).

"It was funny how you can get into a routine of doing that without even realising" (P-09).

In the end, these internalised motivations were not only derived from regulated behaviours, but also from perceiving additional factors such as health. However, it should not be regarded that these motivations were more oriented towards either stimuli. As P-07 states that primary motivation still reside at "making difference in energy" use, and "of course the extra exercising bit too". These results show that participants' autonomous decision-making facilitated the internalisation and it played crucial role for regulations to be integrated into a routinised habit of behaviour.

It is also notable that some level of intrinsic motivation was situated. Beyond the incentives or for any exercise purpose, the HUS introduced an "experience of watching TV more enjoyable" (P-03), "new level of activity into TV watching which is quiet fun" (P-01), and "more enjoyable way of watching TV" (P-02), and participation itself giving enjoyment (P04,08,09). However, not all household occupants took the decision to participate in the HUS, others may have got involved coercively by either their parents or flatmates. Nevertheless, no particular comments were received about any rejection of the new system by these individuals. Although their behaviours were not driven by any extrinsic motivations, or even intrinsic, it is assumed that behaviours were prompted, modelled, or valued by the other household members. As Ryan and Deci (2000) suggest the most powerful influence on intrinsic motivation is 'relatedness' which plays such crucial role in the maintenance of intrinsic motivation.

\subsubsection{New energy saving behaviour}

During the HUS period, the majority of participants observed themselves practicing a new sustainable behaviour such as turning their TV off when not in use. For example, P-06 explained that his behaviour around TV watching had changed to: "when finish we turn it off, 
rather than let the news go on for 10 15 minutes, you are not really watching... so I think you are more likely to not to be induced into catching/wasting 15 20 minutes of program that you are not really watching”. Similar behaviour was observed from P-03,04,09,16 where they were switching the TV off during the adverts, while receiving a phone call, or switching it to 'energy saving mode'. P-15 described that the HUS gave an opportunity for his children to learn about the TV energy saving mode. In addition, some participants performed a new behaviour by replacing the entertainment of the TV with activities such as 'reading' (P-03) or listening to the radio. For example, P-16 described an instance of making an alternative decision during leisure time: "But I found myself thinking, 'well, I just want to relax and watch TV, but I have to pedal', and 'maybe I just listen to radio instead'. So I kind of avoided the TV because of that”. It can be seen that these behaviours are, at some level, linked with introjected regulation where its use induced a psychological motive of avoiding the anxiety of losing human-power credit. For example, many households performed behaviours that avoided losing the credit that they generated; therefore, most of times, "they usually leave the TV on and walk out the room, but I don't think it happened this time. They were switching it off once they went out" (P-15). Whereas P-09 was a frequent radio listener who used TV radio function, but she described how it has changed: “with the radio taking into account that we did have to cycle, we ended up either playing it through one of our phones on the speakers, or just not having it on in the morning”.

\subsection{The role of feedback}

The role of feedback has been perceived as central element in many intervention related studies, and the findings of this study did not vary much from this key emphasis. It has been suggested that the strategy of DfSB needs to be based on the intended user experience (Tromp et al., 2011), and the control spectrum is not a static axis but it can be a fluid depending on individual's perception of the intervention (Wilson et al., 2015). Therefore, the artefact used in this study challenged the existing approach to DfSB by making its function vary within the axis of influence of DfSB strategies. In an attempt to induce sustainable use and to better bring a internalisation, it provides respective interactions through using 'ecofeedback' which confronts the user with behavioural consequences in real-time, 'script' approach to help users gain behavioural goals 'in a more or less forceful way' and avoiding the forced changed by using the 'forced functionality'. The behaviour determinants were derived from the commitment of achieving the goal-set or even a game, and the feedback 
system played a profound role in regulating them into a routine. Within the various different form of extrinsic motivations, the feedback display availed them to gain cognitive map or goal-related regulations; the need for autonomy was identified, and they were integrated into daily routines.

\section{Discussion}

Some quantitative results were also obtained and used during the interview process which needs considerable attention. Only a single household showed an increase of TV watching, whereas all other eight household's TV usage time was decreased during the week ${ }^{8}$. The decrease ranged from a maximum of 4.37 hours to a minimum of 0.4 hours reduced on average. Total calories burned by all 9 participant were 55,321 calories, and the distance of 1217 kilometres travelled that is equivalent to a return road trip from London to Edinburgh. Dean (2008) has provided a calculation that 380 calories are required to power 100 watt colour TV for an hour. If same calculation is used with HUS data, it equals to 146 hours of TV running power generated by all households. However, the total financial incentive generated by all 9 household can still be seen as 'disappointing’ as it is only $£ 1.97$. These figures can be defined as the external benefits gained upon success of 'internalisation of HPP use'. From an individual perspective, this value may not be a significant motivator to maintain the use; but on the other hand, the value may appear as much greater when considering other variables such as health and reducing sedentary behaviour.

It was evident that the HPP intervention contributed to increasing the awareness of energy use around TV usage; however, the result of the HUS and the follow-up email survey showed that the HUS experience was not sufficient to bring a greater impact on a wider scope during and after the post-HUS period, motivating people to perform additional 'energy saving behaviour' with other EuP.

Various different forms of regulations were reported by the HUS participants. These regulating behaviours were not always progressed through each phase of the internalisation process. Rather, it was observed that participants relatively internalise a new behaviour regulation in between any given developing continuum. Some level of 'intrinsic motivation'

\footnotetext{
${ }^{8} 1$ out of 10 household failed to record the quantitative data.
} 
was also situated where users found the activity of using HPP as 'enjoyment', but this was derived from acknowledging the incurring and combined benefits premised on their continuous use. Results of the HUS showed that the type of benefit can vary depending upon the user's goal, value or belief and can either be; the size of the entailing and forthcoming incentive, egoistic value, personal achievements, and health.

\section{Conclusion}

This research investigated using human-power as the main power source for everyday EuP. It viewed the product not merely as an object that simply generates free energy, but instead considered it as an object that people can make sense of, and as a tool to practice energy saving behaviour. This research emphasised for the notion of a sustainable life style by conceptualising the possible future scenario of how an everyday product can be redesigned and developed to encourage alternative energy use.

In the absence of unified framework in assessing the effectiveness of DfSB strategies, this study has followed a deductive process by bringing social-psychological theory to evaluate the strategy used which in turn may reduce the risk of subjective interpretations. It used the HUS to construct active meaning in which the users were engaged both mentally and with real-time actions as they made sense of using human-power as an everyday energy source. It explored different variables that influence the process of internalisation, new habits and perpetuation of using such device for a period of one week. In the context of inducing energy saving behaviour through a product-led intervention, the research explored design applications that are beyond the traditional understanding of user-centred design, making energy-saving activities more attractive. It has considered the notion that the real challenge is sustaining a changed behaviour. Most importantly, in understanding the various forms of controlled motivations, this study suggests that it solely relies on how the system of feedback interacts with the actual users.

Another main challenge for DfSB is to identify a strategy that can transcend the obsolescence of an intervention. The HUS was conducted in the relatively short period of time. Therefore there is an opportunity for future research to further investigate the effectiveness of the intervention through a longitudinal follow-up study. 


\section{References}

Armaroli, N., \& Balzani, V. (2007). The future of energy supply: challenges and opportunities. Angewandte Chemie International Edition, 46, 52-66.

Backlund, S., Gyllenswärd, M., Gustafsson, A., Ilstedt Hjelm, S., Mazé, R., \& Redström, J. (2007). STATIC! The Aesthetics of Energy in Everyday Things. In Design Research Society Wonderground International Conference 2006. Lisbon, Portugal.

Bertoldi, P., \& Atanasiu, B. (2007). Electricity consumption and efficiency trends in the enlarged European Union. IES-JRC. European Union.

Bhamra, T., Lilley, D., \& Tang, T. (2011). Design for Sustainable Behaviour: Using Products to Change Consumer Behaviour. The Design Journal, 14, 427-445.

Boks, C. (2012). Design for Sustainable Behaviour Research Challenges. In M. Matsumoto, Y. Umeda, K. Masui \& S. Fukushige (Eds.), Design for Innovative Value Towards a Sustainable Society (pp. 328-333): Springer Netherlands.

Brey, P. (2006). Ethical aspects of behavior-steering technology. In User Behavior and Technology Development (pp. 357-364): Springer.

Broms, L., Katzeff, C., Bång, M., Nyblom, Å., Hjelm, S. I., \& Ehrnberger, K. (2010). Coffee maker patterns and the design of energy feedback artefacts. In Proceedings of the 8th ACM Conference on Designing Interactive Systems (pp. 93-102): ACM.

Carroll, J., Lyons, S., \& Denny, E. (2014). Reducing household electricity demand through smart metering: The role of improved information about energy saving. Energy Economics, 45, 234-243.

Crabtree, B. F., \& Miller, W. L. (1992). Doing qualitative research. Newbury Park [etc.]: Sage.

Crosbie, T. (2008). Household energy consumption and consumer electronics: The case of television. Energy Policy, 36, 2191-2199.

Darby, S. (2001). Making it obvious: designing feedback into energy consumption. In P. Bertoldi, A. Ricci \& A. de Almeida (Eds.), Energy Efficiency in Household Appliances and Lighting (pp. 685-696): Berlin, Springer-Verlag.

Darby, S. (2006). The Effectiveness of Feedback on Energy Consumption. A Review for DEFRA of the literature on metering, billing and direct displays. In Environmental Change Institute: University of Oxford.

De Young, R. (1993). Changing behavior and making it stick The conceptualization and management of conservation behavior. Environment and Behavior, 25, 485-505.

Dean, T. (2008). The human-powered home choosing muscles over motors. Gabriola Island, B.C.: New Society Publishers.

Deci, E. L., \& Ryan, R. M. (2000). The "What" and "Why" of Goal Pursuits: Human Needs and the Self-Determination of Behavior. Psychological Inquiry, 11, 227268.

Energy Saving Trust (2007). The Ampere Strikes Back. How Consumer Electronics are Taking Over the World. In Energy Saving Trust, London.

Evans, S., Burns, A., Barrett, R., \& Lofthouse, V. (2002). Empathic design tutor: Cranfield University.

Fischer, C. (2008). Feedback on household electricity consumption: a tool for saving energy? Energy Efficiency, 1, 79-104. 
Fitzpatrick, G., \& Smith, G. (2009). Technology-enabled feedback on domestic energy consumption: Articulating a set of design concerns. Pervasive Computing, IEEE, 8, 37-44.

Hargreaves, T. (2010). The visible energy trial: insights from qualitative interviews. Tyndall Centre for Climate Change Research.

Hargreaves, T., Nye, M., \& Burgess, J. (2013). Keeping energy visible? Exploring how householders interact with feedback from smart energy monitors in the longer term. Energy Policy, 52, 126-134.

Jackson, T. (2005). Motivating sustainable consumption : a review of evidence on consumer behaviour and behavioural change : a report to the Sustainable Development Research Network / Tim Jackson. Guildford, Eng.: Centre for Environmental Strategy.

Jansen, A. (2011). Human Power empirically explored. Unpublished PhD Thesis, Delft University of Technology, Delft.

Jansen, A., \& Stevels, A. (2006). Combining eco-design and user benefits from human-powered energy systems, a win-win situation. Journal of Cleaner Production, 14, 1299-1306.

Jelsma, J., \& Knot, M. (2002). Designing environmentally efficient services; a 'script' approach. THE JOURNAL OF SUSTAINABLE PRODUCT DESIGN, 2, 119130.

Jia, D., \& Liu, J. (2009). Human power-based energy harvesting strategies for mobile electronic devices. Frontiers of Energy and Power Engineering in China, 3, 27-46.

Kim, T., Hong, H., \& Magerko, B. (2010). Design requirements for ambient display that supports sustainable lifestyle. In Proceedings of the 8th ACM Conference on Designing Interactive Systems (pp. 103-112): ACM.

Kobus, C. B. A., Mugge, R., \& Schoormans, J. P. L. (2015). Long-term influence of the design of energy management systems on lowering household energy consumption. International Journal of Sustainable Engineering, 8, 173-185.

Lilley, D. (2007). Designing for behavioural change: reducing the social impacts of product use through design. Loughborough University, Loughborough.

Lilley, D. (2009). Design for sustainable behaviour: strategies and perceptions. Design Studies, 30, 704-720.

Lilley, D., Lofthouse, V. A., \& Bhamra, T. A. (2005). Towards instinctive sustainable product use. In 2nd International Conference in Sustainability, Creating the Culture.

Lilley, D., \& Wilson, G. T. (2013). Intergrating Ethics into design for sustainable behaviour. Journal of Design Research, 11, 278-299.

Lockton, D., Harrison, D., \& Stanton, N. (2008). Making the user more efficient: design for sustainable behaviour. International Journal of Sustainable Engineering, 1, 3 - 8.

Norman, D. A. (1999). Affordance, conventions, and design. interactions, 6, 38-43.

Ofcom. (2013). Communications Market Report 2013. In (Vol. 2013).

Owen, P. (2012). Powering the nation-Household electricity-using habits revealed. Energy Saving Trust/DECC/DEFRA, London.

Palmer, J., Terry, N., \& Pope, P. (2012). How much energy could be saved by making small changes to everyday household behaviours? In D. o. E. a. C. Change (Ed.). London: Crown.

Rodriguez, E., \& Boks, C. (2005). How design of products affects user behaviour and vice versa: the environmental implications. In Environmentally Conscious 
Design and Inverse Manufacturing, 2005. Eco Design 2005. Fourth International Symposium on (pp. 54-61): IEEE.

Ryan, R. M., \& Deci, E. L. (2000). Self-Determination Theory and the Facilitation of Intrinsic Motivation, Social Development, and Well-Being. American Psychologist, 55, 68-78.

Selvefors, A., Karlsson, M., \& Rahe, U. (2013). Use and Adoption of Interactive Energy Feedback Systems. Proceedings of IASDR, 1771-1782.

Selvefors, A., Pedersen, K. B., \& Rahe, U. (2011). Design for sustainable consumption behaviour: systematising the use of behavioural intervention strategies. In Proceedings of the 2011 Conference on Designing Pleasurable Products and Interfaces (pp. 3): ACM.

Selvefors, A., Renström, S., \& Strömberg, H. (2014). Design for Sustainable Behaviour: A Toolbox for Targeting the Use Phase. In Eco-design tool conference, May 14-15 2014, Gothenburg, Sweden.

Spaargaren, G. (1997). The ecological modernization of production and consumption: essays in environmental sociology.

Steg, L., \& Vlek, C. (2009). Encouraging pro-environmental behaviour: An integrative review and research agenda. Journal of Environmental Psychology, 29, 309317.

Strengers, Y. A. A. (2011). Designing eco-feedback systems for everyday life. In Proceedings of the 2011 annual conference on Human factors in computing systems (pp. 2135-2144). Vancouver, BC, Canada: ACM.

Tang, T., \& Bhamra, T. (2008). Changing energy consumption behaviour through sustainable product design. In DESIGN 2008, the 10th International Design Conference (pp. 1359-1366). Dubrovnik, Croatia: The Design Society.

Tang, T., \& Bhamra, T. (2012). Putting consumers first in design for sustainable behaviour: a case study of reducing environmental impacts of cold appliance use. International Journal of Sustainable Engineering, 5, 288-303.

Townsend, N., Bhatnagar, P., Wickramasinghe, K., Scarborough, P., Foster, C., \& Rayner, M. (2012). Physical activity statistics 2012. In. London: British Heart Foundation.

Tromp, N., Hekkert, P., \& Verbeek, P.-P. (2011). Design for socially responsible behavior: a classification of influence based on intended user experience. Design Issues, 27, 3-19.

Veerman, J. L., Healy, G. N., Cobiac, L. J., Vos, T., Winkler, E. A. H., Owen, N., \& Dunstan, D. W. (2012). Television viewing time and reduced life expectancy: a life table analysis. British Journal of Sports Medicine, 46, 927-930.

Verplanken, B., \& Wood, W. (2006). Interventions to Break and Create Consumer Habits. Journal of Public Policy \& Marketing, 25, 90-103.

Wever, R., van Kuijk, J., \& Boks, C. (2008). User-centred design for sustainable behaviour. International Journal of Sustainable Engineering, 1, 9-20.

Wilson, G. T., Bhamra, T., \& Lilley, D. (2015). The considerations and limitations of feedback as a strategy for behaviour change. International Journal of Sustainable Engineering, 1-10.

Wilson, G. T., Lilley, D., \& Bhamra, T. (2013). Design feedback interventions for household energy consumption reduction. In 16th Conference of the European Roundtable on Sustainable Consumption and Production (ERSCP) \& 7th Conference of the Environmental Management for Sustainable Universities (EMSU) (ERSCP-EMSU 2013). Istanbul, Turkey. 
Zachrisson, J., \& Boks, C. (2012). Exploring behavioural psychology to support design for sustainable behaviour research. Journal of Design Research, 10, 50-66.

Zachrisson, J., \& Boks, C. (2014). Dimensions of behaviour change. Journal of Design Research, 12, 145-172. 


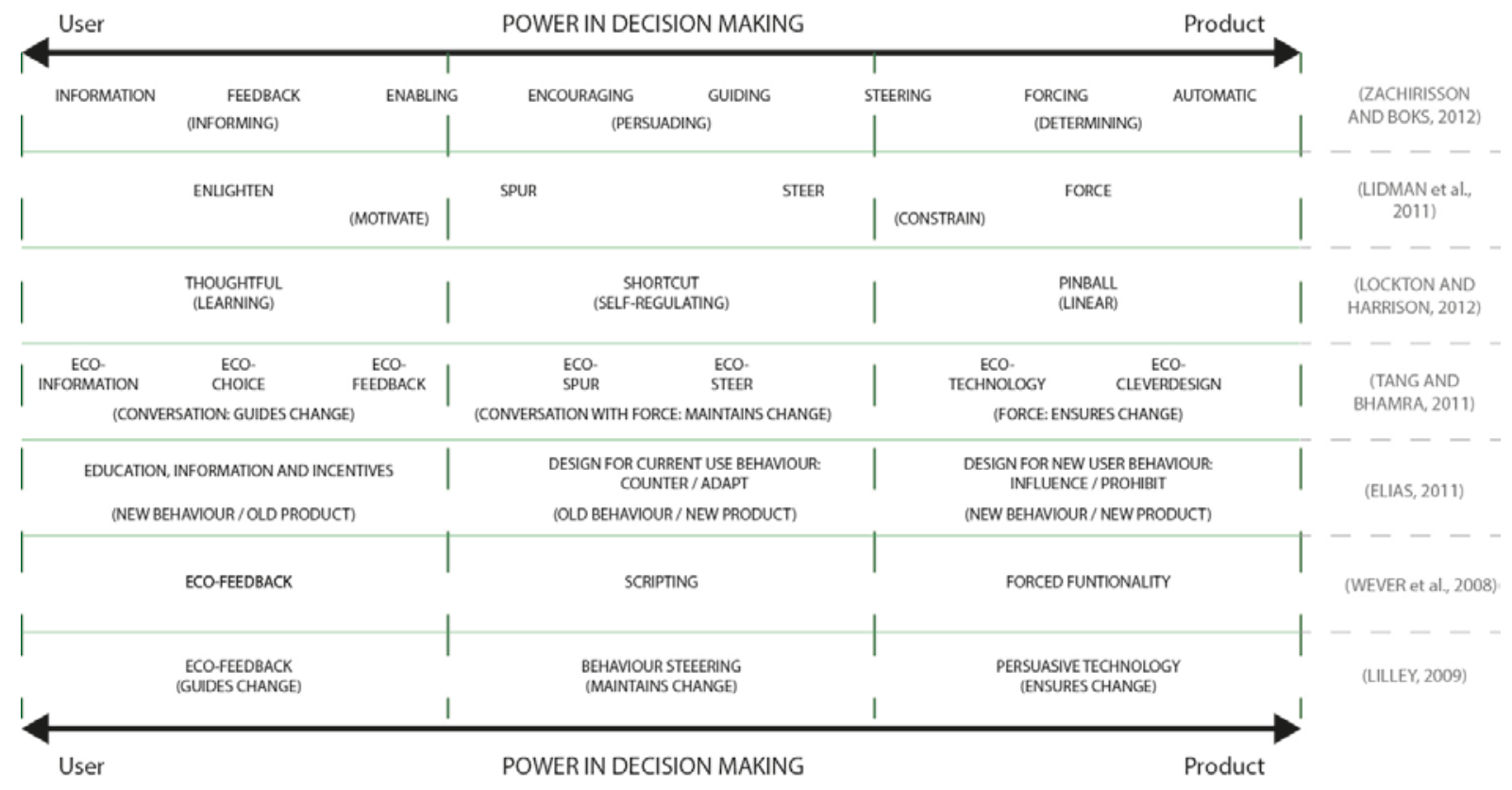

Figure 1 Summary of DfSB strategies (Lilley and Wilson, 2013)
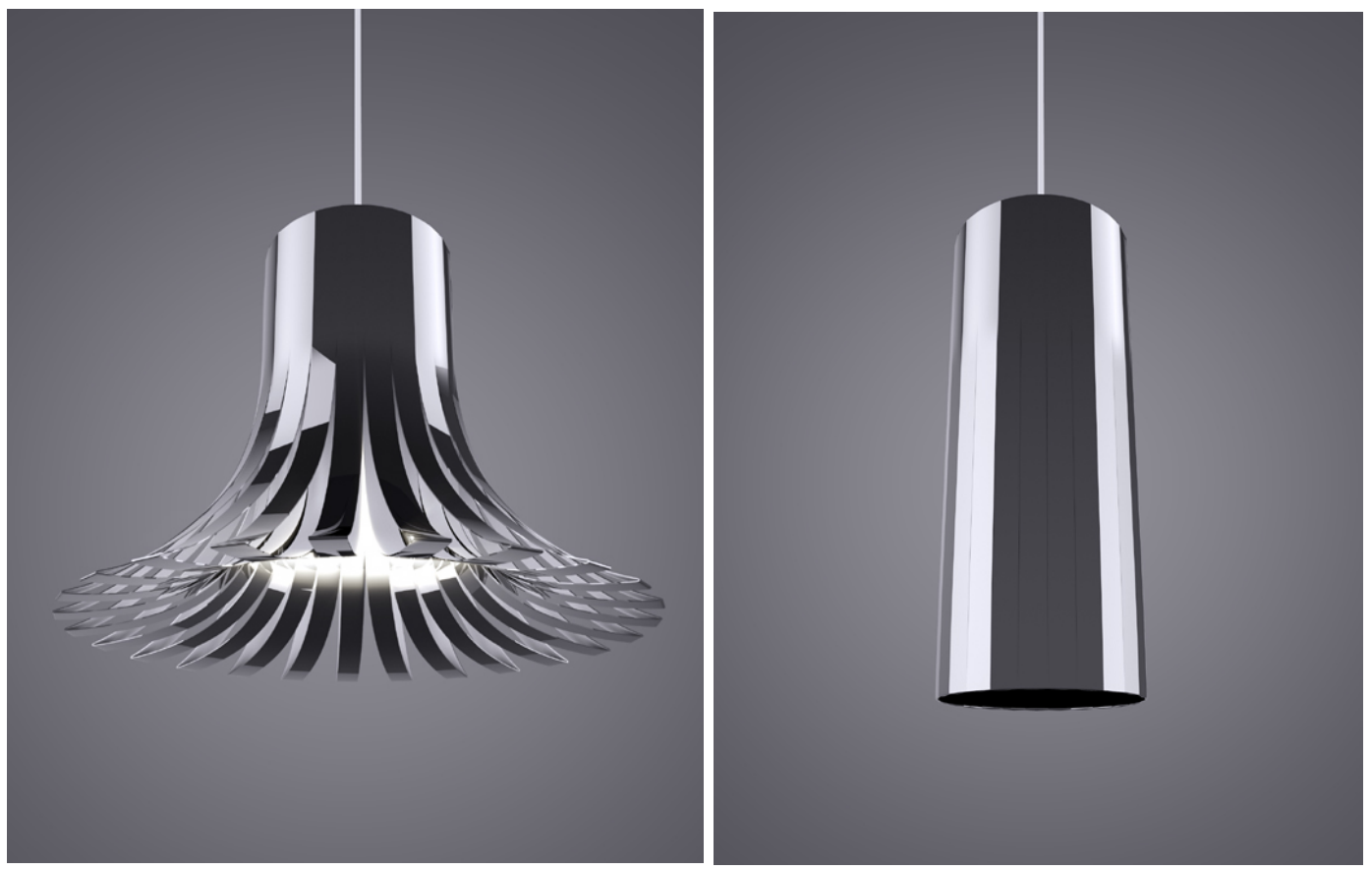

Figure 2 Flower Lamp (Backlund et al., 2007). 
60 min of TV watching $=$ 360 units drop

10 seconds of watching a 110 Watt TV $=1$ unit drop
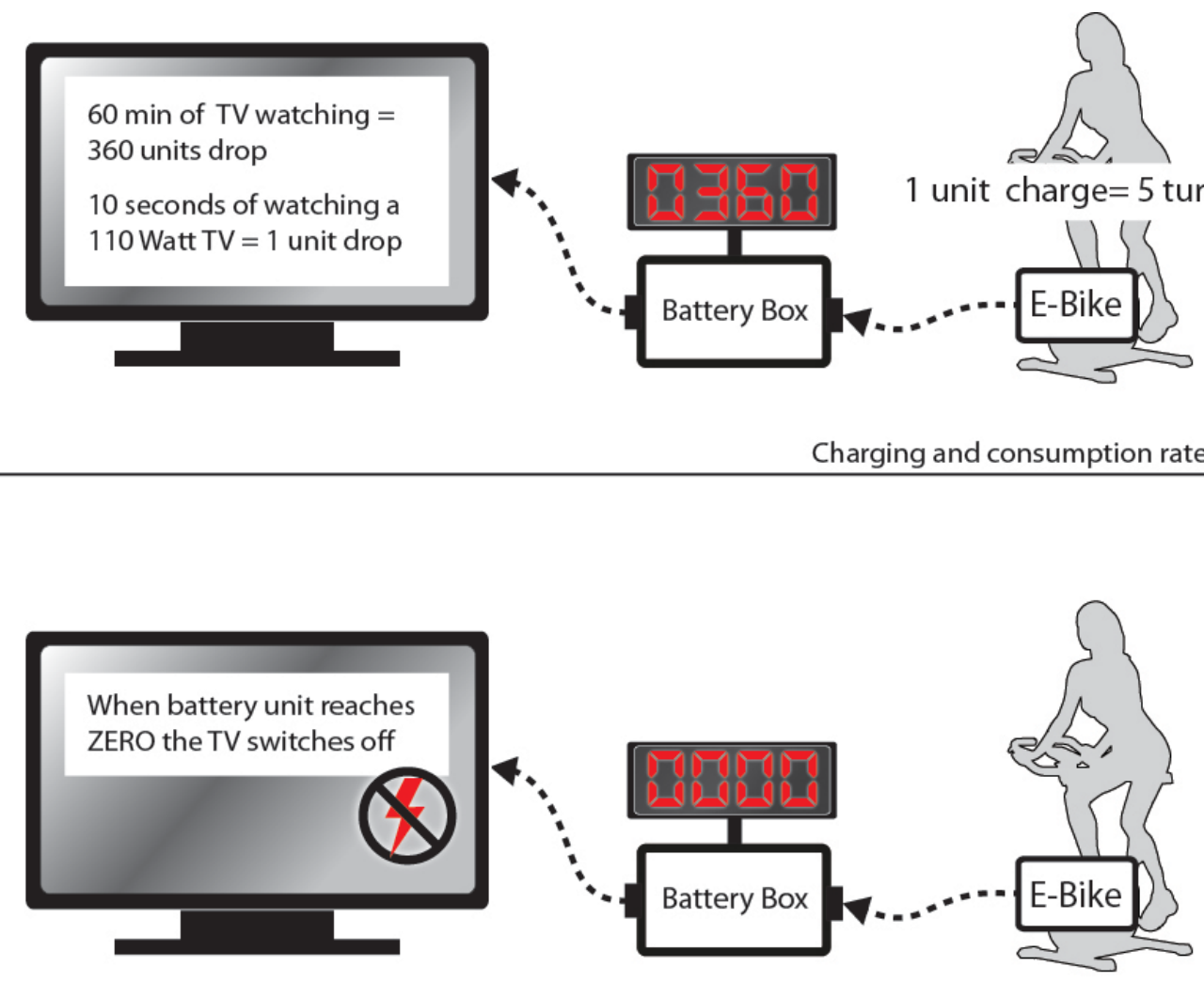

Figure 3 New HPP prototype

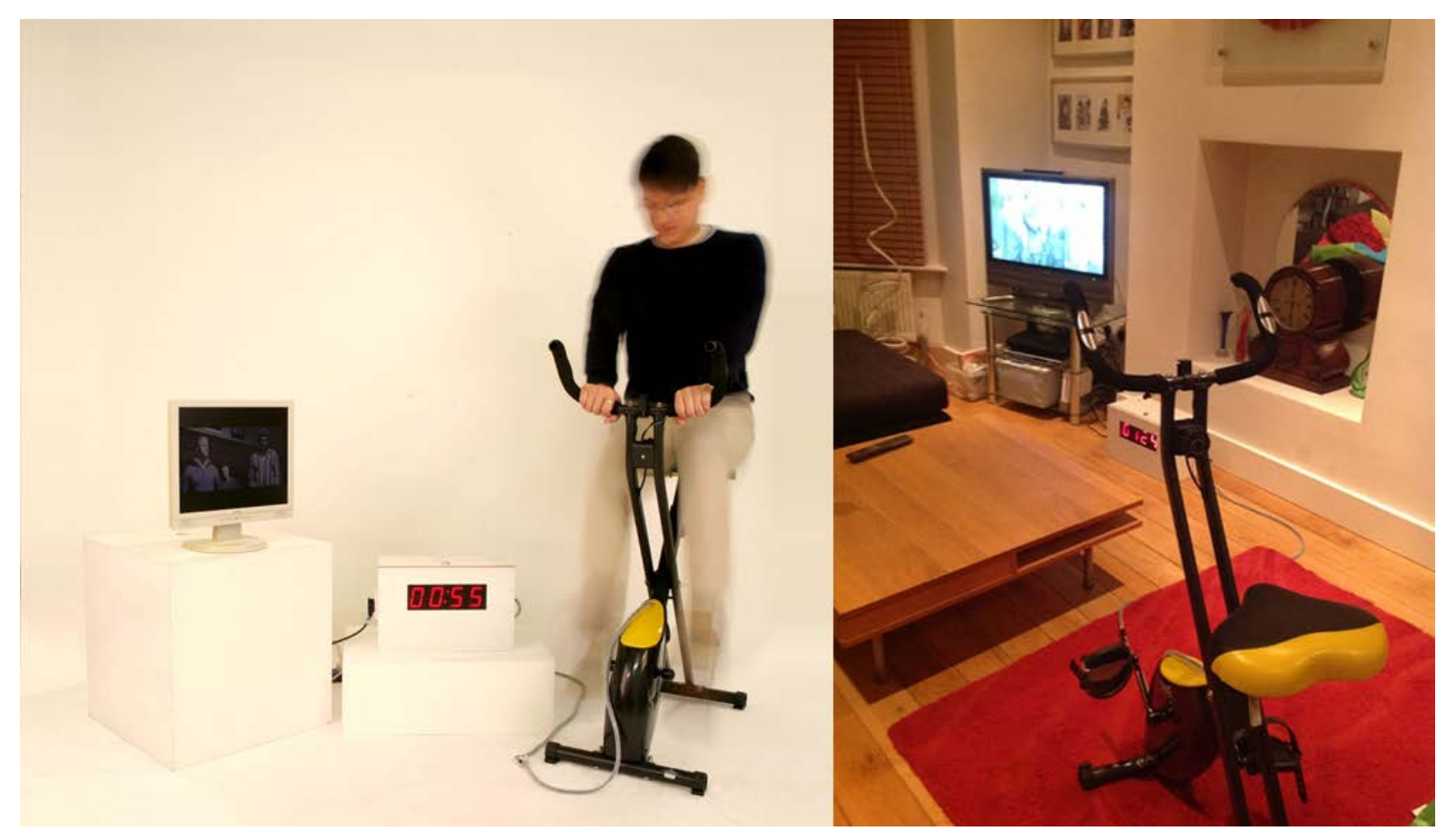

Figure 4 Picture of prototype and HUS scene 


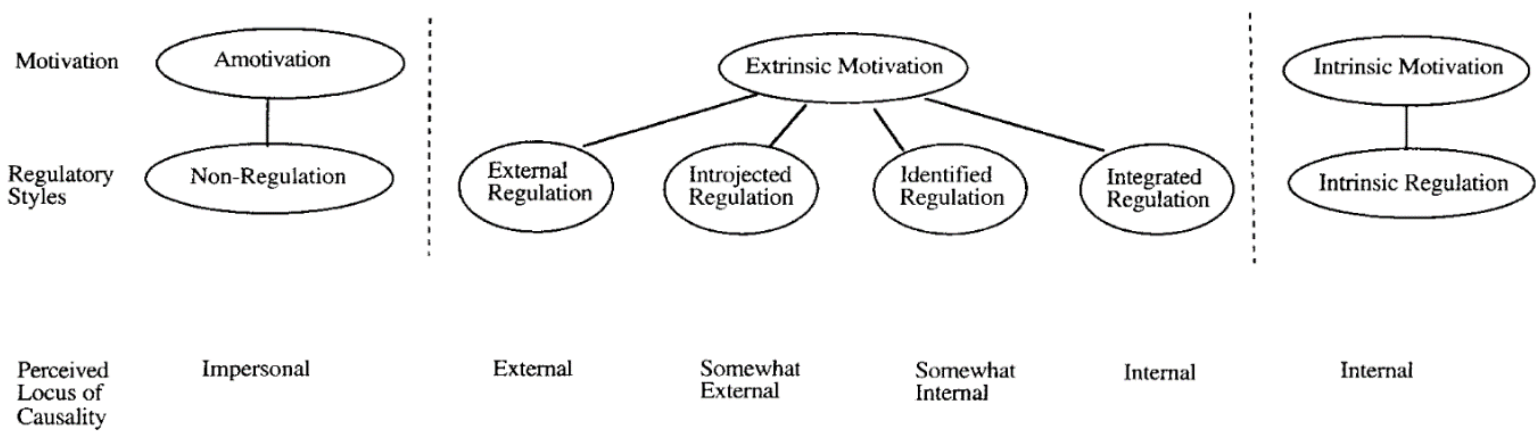

Figure 5 Different types of motivation with their regulatory styles and the locus of causality (Ryan and Deci, 2000) 